\title{
Evaluation of supervised injection facilities as an ethically sound approach to treatment of injection drug abuse
}

\author{
Katherine Fleshner, Matthew Greenacre \\ Faculty Reviewer:Jacob Shelley, LLB, LLM, SJD(c) (Faculty of Law)
}

\begin{abstract}
Novel approaches are needed to address the issue of injection drug use in Canada, which can have negative consequences for drug users and society. Supervised injection facilities (SIFs) are legally sanctioned facilities in Canada where drug users can receive sterile drug paraphernalia, referral to cessation programs and timely medical care if necessary. SIFs operate under the principle of harm reduction, which aims to reduce rates of infection and death due to overdose among drug users. SIFs are largely driven by the utilitarian ideal of maximizing benefit for the greatest number of people, through supervision of active drug users and appropriate referral for those wishing to quit. Deontological theory may support SIFs depending on how one applies the categorical imperative. Studies of the first SIF in North America, Insite, have shown demonstrable reductions in adverse health and societal consequences of injection drug use, rationalizing their implementation under consequentialism. SIFs are, therefore, suitable for greater adoption by the healthcare system.
\end{abstract}

\section{INTRODUCTION}

Injection drug abuse in Canada is a pressing public health issue. Frequently injected drugs include heroin, cocaine, amphetamines and prescription opioids. ${ }^{1}$ Recent data estimate that there are 75000 to 125000 intravenous drug users in the country. ${ }^{1}$ Injection drug use is problematic due to its association with addiction, fatal overdose, contraction of chronic infections such as Human Immunodeficiency Virus (HIV) or Hepatitis C, social isolation and criminal behaviours. ${ }^{1}$ Novel approaches to facilitating cessation of intravenous drug use are needed to ameliorate this issue.

Supervised injection facilities (SIFs) are legally sanctioned medical facilities within which individuals may consume illicit drugs under the supervision of healthcare workers. These centers operate under the principle of harm reduction, which aims to circumvent the adverse effects of drug consumption rather than absolutely discourage use altogether. ${ }^{2}$ They provide sterile injection equipment to prevent the spread of infection often seen with needle-sharing and using unsanitary drug paraphernalia, including needles, cookers and tourniquets. Opiate antagonists such as naloxone are available on site to be administered in the event of an overdose. SIFs staff includes social workers and mental health workers who provide services including counseling and information about and referral to rehabilitation programs.

The first SIFs were established in the Netherlands in the 1970s as a result of changing attitudes towards deviant youth behaviours including drug use. ${ }^{3}$ These centres were designed as a communal meeting place and drop-in facility where individuals could consume drugs. Some basic health services were also provided onsite. ${ }^{3}$ In following years, similar centres were established in Switzerland and Germany. ${ }^{3}$

In 2003, Insite, the first SIF in North America, opened in Downtown Eastside, Vancouver as a pilot project for a novel harm reduction approach to substance abuse. Downtown Eastside is the poorest urban neighbourhood in Canada with an estimated 5000 injection drug users. ${ }^{4}$ Insite was initially granted a special threeyear exemption from Section 56 of the Controlled Drugs and Substances Act, which prohibits possession and trafficking of illicit drugs, on the condition that its effects on the community be studied. ${ }^{5}$ The exemption was extended until 2007, after which a constitutional challenge to Section 56 was filed to the Supreme Court of British Columbia. Plaintiffs argued that it is unconstitutional to prohibit possession and trafficking of illicit drugs as it restricts drug users' access to SIFs such as Insite. ${ }^{6}$ The Supreme Court of British Columbia and, subsequently, the Supreme Court of Canada ruled in their favour, granting Insite a constitutional exemption of Section 56 to allow them to continue operation. ${ }^{7}$ In 2017 thus far, Health Canada has approved the opening of three new SIFs in Montreal and three in Toronto, and they are currently reviewing applications for additional SIFs in Surrey and Vancouver. ${ }^{8,9}$

SIFs are controversial. While other drug therapy practices such as methadone clinics are funded by provincial healthcare systems, many question whether the Canadian healthcare system should subsidize or even simply condone a practice that facilitates drug consumption rather than seeking to abolish it. ${ }^{10,11}$ This article will demonstrate that utilitarianism and consequentialism provide an ethical foundation for the Canadian healthcare system to adopt SIFs as a complementary approach to treatment of injection drug abuse.

\section{UTILITARIANISM, CONSEQUENTIALISM AND DEONTOLOGY}

Ethical examination of a practice typically consists of two schools of thought: utilitarianism and deontology. Utilitarianism, pioneered by Jeremy Bentham and John Stuart Mill, teaches that an action is moral if it maximizes the happiness within a society. ${ }^{12}$ Utilitarianism is sometimes considered under the broader theory of consequentialism. In judging the morality of an action or policy, consequentialism considers the widespread impact of an action on all stakeholders as well as society at large.$^{13}$ Consequentialism and utilitarianism justify an action based upon the goodness of the results it produces, regardless of the optics or inherent righteousness of the action itself. ${ }^{12}$ 
In contrast to utilitarianism, deontological theory as put forth by Immanuel Kant states that humans are rational beings, and rational beings cannot be used as a means to an end. ${ }^{14}$ Therefore, deontology judges morality by inherent goodness and whether actions are motivated by duty, irrespective of the consequences. ${ }^{12}$ Inherent goodness is often evaluated by whether an action or policy can conform to the categorical imperative, which poses that inherently moral actions could be prescribed as a universal law. ${ }^{12}$

\section{SUPERVISED INJECTION FACILITIES MAXIMIZE GOOD FOR MORE DRUG USERS}

An ideal utilitarian approach to the issue of substance abuse would bring about the most happiness for the greatest number of people. However, many of the current approaches to treatment for substance abuse are rooted in an abstinence-only philosophy whereby help is provided to those willing to completely cease use. These programs only benefit a subset of drug users: those who are willing, ready and able to stop using. A significant proportion of drug users do not fall under those categories for a multitude of reasons, such as a desire to continue using or an inability to quit. These individuals are therefore unaddressed by the abstinence-only approach. ${ }^{1}$

In contrast, harm reduction programs such as SIFs provide more holistic care for drug users. In addition to the services provided in association with supervised injection, SIFs employ on-site counselors, physicians and mental health workers to assist individuals who express a willingness to quit. Some SIFs either have adjacent detoxification facilities or are closely affiliated with similar facilities in the community. ${ }^{15}$ Therefore, SIFs help more people than would a strict cessation program, and therefore are more utilitarian in nature.

\section{DEONTOLOGICAL THEORY MAY CONFLICT WITH HARM REDUCTION PRINCIPLES}

The deontological approach to substance abuse would conform to the categorical imperative, which states that a truly moral action could be prescribed as a universal law. However, drug users comprise a rather small subset of the population, and so it is hard to delineate whether the categorical imperative should consider a proposed policy as universal law only for those who consume drugs or for all members of society. In the case of SIFs, if one considered all of society, a possible universal law might be, 'everyone should consume drugs in SIFs'. However, as intoxication and/or addiction eliminate an individual's autonomy and free choice, ${ }^{14,16,17}$ if everyone were to consume drugs, it would impair all individuals' ability to act as rational beings - a central tenet of deontological theory. Therefore, this cannot align with a deontological viewpoint. However, if the categorical imperative instead applied only to drug users, and the universal law became, 'all drug users should consume in SIFs', then a rationale becomes evident. If all drug users consumed in SIFs, then the rates of fatal overdoses and injection-related infections would be markedly reduced - the result of close surveillance and education by medical personnel. In addition, public drug use and drug litter would be virtually eradicated since everyone would only consume within SIFs.

\section{CONSEQUENTIALIST EVALUATION OF SUPERVISED INJECTION FACILITIES SUPPORTS THEIR ADOPTION}

Rampant drug use detrimentally impacts the communities in which it occurs. Oftentimes, communities with significant populations of drug users have associated high rates of public drug use and public discarding of syringes, which can put other citizens at risk for needle-stick injuries. ${ }^{1,4,18}$ The presence of drug dealers and higher rates of petty crime may also pose safety issues. ${ }^{1}$ In the neighbourhood of Downtown Eastside, Vancouver, the rates of Hepatitis $\mathrm{C}$ and HIV infection are $90 \%$ and $30 \%$, respectively, ${ }^{1,19}$ and rates of fatal overdose and emergency care use are exceedingly high relative to surrounding communities. ${ }^{20}$

Two years after Insite opened in Downtown Eastside, rates of syringe sharing declined among individuals who injected within the facility, whereas no change in syringe sharing patterns were noted in individuals not injecting at Insite. ${ }^{21}$ Insite users also received education about how to inject to avoid infection and subsequently adopted sterilization regimens prior to injection. ${ }^{21}$ Utilization of Insite facilities was also associated with decreased syringe lending by HIV-positive drug users and decreased syringe borrowing by HIV-negative drug users. ${ }^{21}$ Downtown Eastside also noted decreases in public injection of drugs and in publicly discarded syringes and other forms of injection-related litter. ${ }^{21}$ With respect to medical complications of injection drug use, Insite has prevented approximately 35 new cases of HIV and 3 deaths due to overdose each year - a net societal benefit of almost $\$ 6$ million per year. ${ }^{22}$ Furthermore, rates of overdose at Insite were remarkably low and the majority that did occur were managed onsite by in-house staff, ${ }^{21}$ subverting the need for external emergency care. The overall overdose rate in the community surrounding Insite fell by $35 \%$ in the two year period following its opening. ${ }^{23}$ Suspected drug dealing and drug-related crime also did not increase during this time. ${ }^{21}$ Insite has led to positive outcomes within the community of Downtown Eastside, justifying its operation under consequentialist ideals.

\section{CONCLUSION}

As demonstrated, SIFs find footing on utilitarian and consequentialist bases by minimizing the harms associated with ongoing drug use and assisting those who are ready to quit. Unlike previous approaches that stress abstinence from drugs, SIFs promote individual freedoms and also prevent further harm through distribution of clean drug paraphernalia and timely medical attention in the case of an overdose. On a societal level, the implementation of SIFs can lead to both subsequent decreases in public drug injection and public discarding of syringes with no associated increase in drug-related crimes. SIFs are, therefore, well suited for adoption by the Canadian healthcare system for treatment of drug abuse. 


\section{REFERENCES}

1. Supervised Injection Facilities (SIFs): FAQs [Internet]. Canadian Centre on Substance Abuse; [cited 2017 Mar 11]. Available from: http:// www.ccsa.ca/Resource Library/ccsa-010657-2004.pdf.

2. Erickson PG. Harm reduction: what it is and is not. Drug Alcohol Rev. 1995;14(3):283-5.

3. Dolan K, Kimber J, Fry C, et al. Drug consumption facilities in Europe and the establishment of supervised injecting centres in Australia. Drug Alcohol Rev. 2000;19(3):337-46.

4. Wood E, Kerr T, Small W, et al. Changes in public order after the opening of a medically supervised safer injecting facility for illicit injection drug users. CMAJ. 2004;171(7):731-4

5. Wood E, Kerr T, Lloyd-Smith E, et al. Methodology for evaluating Insite: Canada's first medically supervised safer injection facility for injection drug users. Harm Reduct J. 2004;1(1):9.

6. Makin K, Dhillon, S, Peritz, I. Supreme Court ruling opens doors to drug injection clinics across Canada [Internet]. The Globe and Mail. September 30, 2011 [cited 2017 May 25]. Available from: http://www. theglobeandmail.com/news/british-columbia/supreme-court-rulingopens-doors-to-drug-injection-clinics-across-canada/article4182250/.

7. Canada (Attorney General) v. PHS Community Services Society, 2011 SCC 44, [2011] 3 S.C.R. 134. Cited 2017 May 24. Available from: https:// scc-csc.lexum.com/scc-csc/scc-csc/en/item/7960/index.do.

8. Woo A, Perreaux, L. Health Canada approves three supervised consumption sites for Montreal [Internet]. The Globe and Mail. [cited 2017 May 25]. Available from: http://www.theglobeandmail.com/ news/politics/federal-government-approves-three-supervised-injection-sites-in-montreal/article33914459/.

9. Woo A, Gray, Jeff. Federal government approves three supervised-injection sites in Toronto [Internet]. The Globe and Mail. 2017 Jun 02 [cited 2017 Jun 13]. Available from: http://www.theglobeandmail.com/ news/national/federal-government-approves-three-supervised-injection-sites-in-toronto/article35189403/.

10. Stueck W. The arguments for and against Vancouver's supervised injection site [Internet].2011 [cited 2017 Mar 11]. Available from: http://www.theglobeandmail.com/news/british-columbia/the-arguments-for-and-against-vancouvers-supervised-injection-site/article596153/.

11. Strike C, Watson TM, Kolla G, et al. Ambivalence about supervised injection facilities among community stakeholders. Harm Reduct J. 2015;12:26.

12. Christie T, Groarke L, Sweet W. Virtue ethics as an alternative to deontological and consequential reasoning in the harm reduction debate. Int J Drug Policy. 2008;19(1):52-8.

13. Sinnott-Armstrong W. Consequentialism [Internet]. 2003 [cited 2017 Jun 13]. In: The Stanford Encyclopedia of Philosophy [Internet]. Metaphysics Research Lab, Stanford University. Available from: https:// plato.stanford.edu/cgi-bin/encyclopedia/archinfo.cgi?entry=consequentialism.

14. Kant I. The Doctrine of Virtue. Ethics. 1965;75(2):142-3.

15. Small W, Van Borek N, Fairbairn N, et al. Access to health and social services for IDU: The impact of a medically supervised injection facility. Drug Alcohol Rev. 2009;28(4):341-6.

16. Leshner AI. Addiction is a brain disease, and it matters. Science. 1997;278(5335):45-7.

17. Lyvers M. "Loss of control" in alcoholism and drug addiction: a neuroscientific interpretation. Exp Clin Psychopharmacol. 2000;8(2):225-49.

18. Doherty MC, Junge B, Rathouz P, et al. The effect of a needle exchange program on numbers of discarded needles: a 2-year follow-up. Am J Public Health. 2000;90(6):936-9.

19. Tyndall MW, Kerr T, Zhang R, et al. Attendance, drug use patterns, and referrals made from North America's first supervised injection facility. Drug Alcohol Depend. 2006;83(3):193-8.

20. Palepu A, Tyndall MW, Leon H, et al. Hospital utilization and costs in a cohort of injection drug users. CMAJ. 2001;165(4):415-20.

21. Wood E, Tyndall MW, Montaner JS, et al. Summary of findings from the evaluation of a pilot medically supervised safer injecting facility. CMAJ. 2006;175(11):1399-404.

22. Andresen MA, Boyd N. A cost-benefit and cost-effectiveness analysis of Vancouver's supervised injection facility. Int J Drug Policy. 2010;21(1):70-6.

23. Marshall BD, Milloy MJ, Wood E, et al. Reduction in overdose mortality after the opening of North America's first medically supervised safer injecting facility: a retrospective population-based study. Lancet. 2011;377(9775):1429-37. 